\title{
Effectiveness of Intra-anal Biofeedback and Electrical Stimulation in the Treatment of Children With Refractory Monosymptomatic Nocturnal Enuresis: A Comparative Randomized Controlled Trial
}

\author{
Seham Mohammed Abd El-Moghny ${ }^{1}$, Manal Salah El-Din ${ }^{2}$, Samah Attia El Shemy ${ }^{2}$ \\ ${ }^{1}$ Department of Physical Therapy, Banha Teaching Hospital, Qalyubia, Egypt \\ ${ }^{2}$ Department of Physical Therapy for Pediatrics, Faculty of Physical Therapy, Cairo University, Giza, Egypt
}

\begin{abstract}
Purpose: To compare the effects of intra-anal biofeedback (BF) and intra-anal electrical stimulation (ES) on pelvic floor muscles (PFMs) activity, nocturnal bladder capacity, and frequency of wet night episodes in children with refractory primary monosymptomatic nocturnal enuresis (PMNE).

Methods: Ninety children of both sexes aged 8-12 years with refractory PMNE participated in this study. They were randomly assigned to 3 groups of equal number: control group $(\mathrm{CON})$ that underwent behavioral therapy and PFM training, and 2 study groups (BF and ES) that underwent the same program in addition to intra-anal BF training and intra-anal ES, respectively. PFMs activity was assessed using electromyography, nocturnal bladder capacity was evaluated by measuring the first morning voided volume, and a nocturnal enuresis diary was used for documenting wet night episodes before treatment and after 3 months of treatment.

Results: After training, all groups showed statistically significant improvements in all measured outcomes compared to their pretreatment findings. The ES group showed significantly greater improvements in all measured outcomes than the CON and BF groups.

Conclusions: Both intra-anal BF training and ES combined with behavioral therapy and PFMs training were effective in the treatment of PMNE, with intra-anal ES being superior to BF training.
\end{abstract}

Keywords: Electromyography biofeedback; Electrical stimulation; Refractory monosymptomatic nocturnal enuresis

- Research Ethics: The study was approved by the Ethics Review Committee of the Faculty of Physical Therapy, Cairo University (approval number: P.T.REC/012/00903).

- Conflict of Interest: No potential conflict of interest relevant to this article was reported.

\section{INTRODUCTION}

Nocturnal enuresis (NE) has been identified by the International Children's Continence Society (ICCS) as intermittent incontinence during sleeping periods with the inability to awaken to the signal of a full bladder [1]. Children over the age of 5 years who are unable to accomplish 6 successive months of nighttime dryness are said to have primary nocturnal enuresis (PNE). On the basis of the presence or absence of associated lower urinary tract symptoms, enuresis is categorized into nonmonosymptomatic (NMNE) and monosymptomatic (MNE) types, respectively [2]. Despite several treatment strategies,

Corresponding author: Samah Attia El Shemy (D) https://orcid.org/0000-0002-7599-5212 Department of Physical Therapy for Pediatrics, Faculty of Physical Therapy, Cairo University, 7 Ahmed Elzayat Street, Dokki, Giza 12612, Egypt

E-mail: samah_elshemy@yahoo.com / Tel: +20-237617691 / Fax: +20-237617692

Submitted: June 23, 2018 / Accepted after revision: August 25, 2018 
some children are resistant or refractory to the standard therapy, which is challenging to their families and has a major influence on their quality of life. Therefore, it is essential to search for an effective treatment in order to minimize the multi-factorial effects of this condition [3].

During the first 2 years of life, micturition occurs reflexively, stimulated by bladder fullness, leading to detrusor contraction and external sphincter relaxation. Bladder fullness awareness emerges during the second year, but uninhibited detrusor contractions (UDCs) cause the child to void suddenly [4]. Continence is accomplished by external striated sphincter control during the third year, with subsequent detrusor muscle control during the fourth year, and finally the child achieves control over reflexive micturition and UDC during the fifth year through central nervous system development [5].

The neural reflex arc of bladder function control is affected in children with primary MNE, (PMNE) causing hypoexcitability of the sphincter nuclei with hyperexcitability of the bladder motor nuclei, leading to impairment of both sphincter muscle activation and detrusor inhibition [6]. The impaired reflex arc manifests as slowed conduction velocity of both the pudendal and tibial nerves. The impeded afferent pathway interferes with conveying the signals to the spinal or cortical area, which changes the child's arousal, leading to overactive bladder due to lack of inhibition from the micturition center [7].

There is a direct relationship between urinary continence and pelvic floor muscles (PFM) activity [8]. The pudendal nerve innervates all the PFMs, including the external anal and urethral sphincters. External anal sphincter activity is considered to be an indicator of external urethral sphincter function [9]. Detecting the electromyographic (EMG) signals of PFMs from the intra-anal or rectal probes is preferable to perianal surface EMG in order to avoid false EMG activity from other nearby muscles [10].

Nocturnal enuresis manifests through the presence of nocturnal polyuria, nocturnal bladder overactivity, and sleep arousal difficulties [11]. Therefore, treatment focuses on behavior modification, restricting night fluid intake, setting bedwetting alarms, waking up the child intermittently to void, and pharmacotherapy [12].

Biofeedback PFMs training is effective for the treatment of pelvic floor disorders. It controls enuresis frequency and normalizes bladder capacity through enhancing PFMs function and sphincteric neuromotor control [13]. Biofeedback (BF) training with anal pressure monitoring is a technique used in
PFMs training [10]. Muscle activity has been displayed as audiovisual signals through animated BF games, which assist in enhancing the efficiency of training by giving positive reinforcement in a play environment [14].

Electrical stimulation (ES) of the PFMs can be delivered vaginally, anally, percutaneously, or transurethrally. The effects of ES methods, including transcutaneous electrical nerve stimulation, posterior tibial nerve stimulation, and transcutaneous interferential ES in children with PMNE have been investigated and have shown promising impacts on normalizing enuresis frequency, detrusor overactivity, and bladder capacity [15-18].

Therefore, the current study aimed to compare the treatment outcomes of intra-anal BF training and intra-anal ES in terms of PFMs activity peak and speed, nocturnal bladder capacity, and the frequency of wet night episodes in children with PMNE refractory to medical treatment.

\section{MATERIALS AND METHODS}

\section{Participants}

A total of 100 children of both sexes suffering from refractory PMNE were assessed for eligibility for this study. They were recruited from outpatient clinic of urology of Banha Teaching Hospital, Egypt. Five children did not meet the inclusion criteria and the parents of the other 5 children refused to allow them to participate in the study. The study was conducted on the remaining 90 children (77 boys and 13 girls) who met the following inclusion criteria: (1) their ages ranged from 8 to 12 years and they had a history of 3 or more wet nights per week for 6 successive months; (2) they were resistant to medical treatment, as shown by having taken medications for at least 6 months with an unfavorable response; (3) they had discontinued medical treatment at least 1 month before the initial assessment; and (4) they were able to follow instructions during the testing and treatment procedures. Children were excluded from this study if they had NMNE, diabetes mellitus, a history of anal problems, visual perceptual disorders, hearing deficits, or attention or learning difficulties. The recruitment process and the flow chart of the study design are presented in Fig. 1.

This study was a randomized controlled trial carried out in accordance with the Code of Ethics of the World Medical Association (Declaration of Helsinki) for experiments involving humans. The study was approved by the Ethics Review Committee of the Faculty of Physical Therapy, Cairo University (approval number: P.T.REC/012/00903). Before the initiation of 


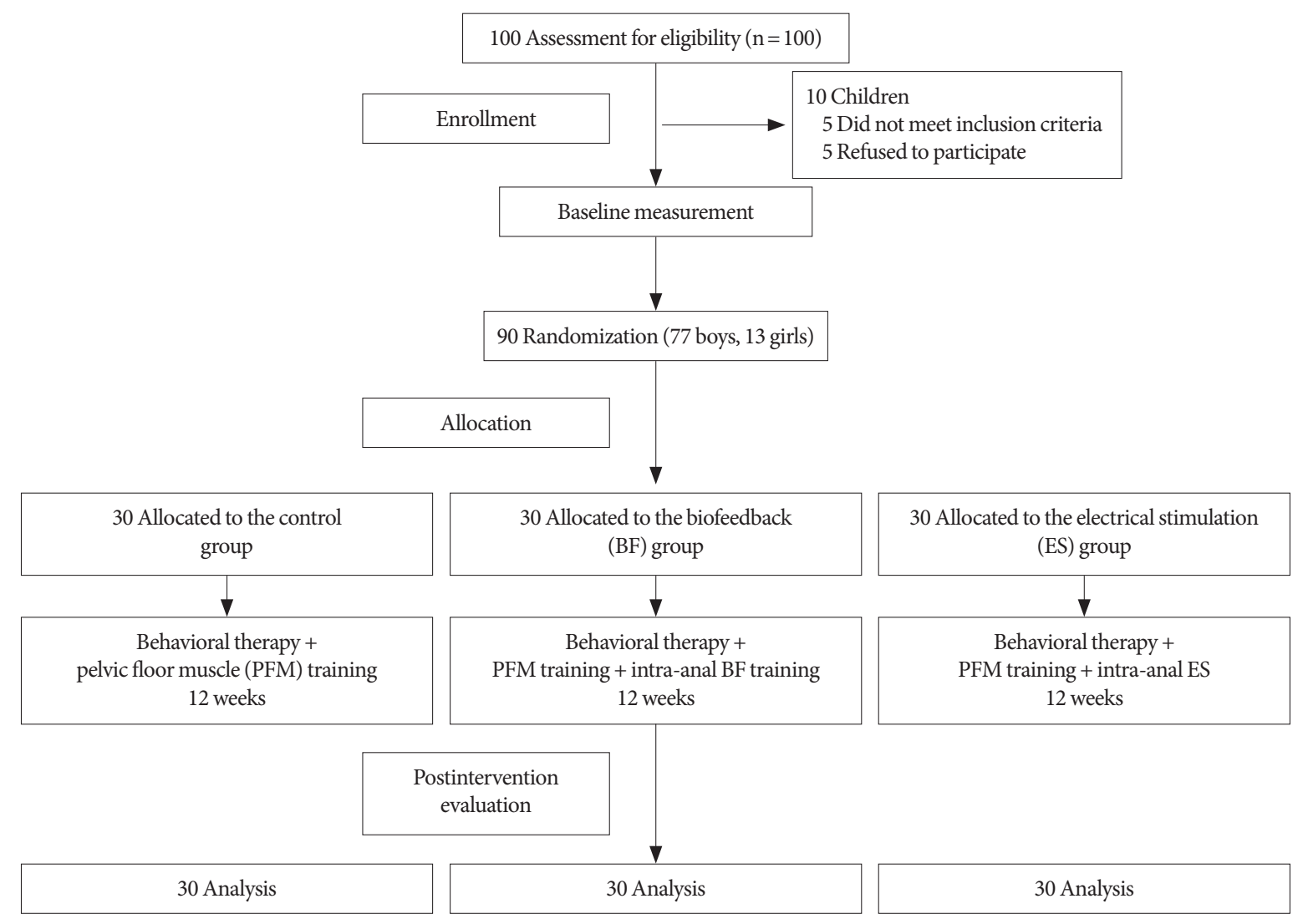

Fig. 1. Flow chart of the study design.

the study, the purposes, procedures, and benefits were fully explained to the participating children and their parents. Informed consent was obtained from all parents, who approved their children's participation in the current study.

\section{Randomization}

The participating children were randomly allocated using the sealed envelope method into 3 groups containing 30 children each. The control (CON) group underwent behavioral therapy and PFMs training. The study groups (the BF and ES groups) underwent the same program given to the CON group in addition to intra-anal BF training and intra-anal ES, respectively. The randomization process was carried out by a researcher who was not involved in any other part of the study.

\section{Outcome Measures}

All children were evaluated before the commencement (pretreatment) and after 3 successive months of treatment (posttreatment). The activity of PFMs (peak and speed) was assessed by surface EMG (sEMG), nocturnal bladder capacity was evaluated by measuring the first morning voided volume (FMV) using a urinal, and NE diary was used to register wet night episodes.

\section{Procedures for Evaluation} Assessment of PFMs activity

Pelvic floor muscles activity was evaluated using EMG (Gymna Unify 200, Gymna, Bilzen, Belgium). It is equipped with a surface mono-polar reference electrode and an endo-anal sensor, which is used for recording PFMs activity (peak and speed). Its small surface makes it less sensitive to cross-talk, and its notched shape ensures optimal placement with a standard location for orientation and depth [19].

Prior to evaluation, children were instructed to avoid intense physical activity and to void and empty their rectum. Each child was tested from the crook-lying position with $45^{\circ}$ of knee flexion with the legs slightly abducted. The mono-polar adhesive reference electrode was applied over the right anterior superior iliac spine (ASIS) after rubbing the electrode site with an alcohol swab to ensure good skin impedance [20]. The endo-anal EMG sensor was inserted using a small amount of antiallergic lubricant. 
During the testing session, children were completely covered with a blanket to maintain their privacy and each child was instructed to not adduct the legs and to relax the abdominal muscles as much as possible [21]. Following the protocol of Grape et al. [22], each child was asked to do 3 PFM contractions within 1 minute as strongly as possible with 10 seconds of hold and 10 seconds of rest. The contraction with the superior value was chosen for data analysis. PFM activity was assessed by measuring the peak of muscle contraction, defined as the difference between the maximum value and the relaxed baseline value $(\mu \mathrm{V})$, and the speed of contraction, defined as the peak divided by the time it took to reach the peak $(\mu \mathrm{V} / \mathrm{sec})$.

\section{Assessment of nocturnal bladder capacity}

Nocturnal bladder capacity was evaluated by measuring the FMV volume, using a urinal, just after the child got up in the morning.

\section{Assessment of wet night episodes}

The children and their parents were instructed to keep NE diary in order to document the number of wet nights throughout the period of the study. The clinical response to treatment was assessed as outlined by the new ICCS definition according to the percentage of reduction in wet nights, as follows: non-response ( $<50 \%$ reduction in wet nights), partial response $(50 \%-$ $99 \%$ reduction), or response (100\% reduction) [2]. Accordingly, to represent a starting point, parents were instructed to document wet nights for 1 month before beginning the treatment.

\section{Procedures for Treatment \\ Biofeedback PFMs training}

Children in the study group (BF) underwent intra-anal BF training with animated games using the Gymna Myo 200. It is equipped with an anal pressure probe, 2 sEMG electrodes, a mono-polar reference electrode, and various animated games for the application of BF training. Initially, each child was trained to perform quick flicks of PFMs contractions with relaxed abdominal muscles.

From the crook-lying position, the anal pressure probe enclosed in a lubricated condom was inserted into the child's anus after rubbing the skin with an alcohol swab. Two surface adhesive electrodes were applied on the rectus abdominis muscle to pick up the substitution signals that hinder the PFMs activity [23]. The surface reference electrode was placed over the right ASIS. Each child was shown different games and chose one for training (e.g., a flying helicopter, a swimming duck, a car race, a smiley face, a balance ball, a penguin fish hunter, a weightlifter cat).

At the beginning of each session, the threshold value was determined by asking the child to perform a single contraction with as much force as possible, and the sub threshold value was then used for training. Each child tracked the previously selected game on the computer screen in which movement corresponded to his/her PFMs contraction and relaxation [23]. During the session, the anal sphincter pressure was monitored through audiovisual stimuli reflecting PFMs activity and a warning sound indicating undesired abdominal muscles activity. Each session lasted 30 minutes and it could be paused according to the child's tolerance [14]. Training of PFMs was applied for 3 sessions per week for 3 successive months.

\section{Pelvic floor ES}

Children in the study group (ES) underwent intra-anal ES using the Gymna Myo 200. It is equipped with an intra-anal probe and an adhesive surface electrode. The intra-anal probe has a rectal component with an angle of $45^{\circ}$ that ends in a 15 mm stimulating spherical tip. This angled shape permits the stimulating tip to be directed inside the rectum to reach the pudendal nerve. The pudendal nerve stimulation site was identified by introducing the therapist's lubricated gloved index finger into the rectum to palpate the ischial spines bilaterally. The distance of the index finger needed to reach the ischial spine was measured, and the sterilized intra-anal probe was then inserted for the same distance into the anus, with an antiallergic lubricant, to stimulate the right and left pudendal nerves [24]. The other adhesive surface electrode was applied at the pubic symphysis. Visible contraction of the PFMs and external anal sphincter were observed to ensure the correct stimulation site of the pudendal nerve.

Low-amplitude current stimulation was used with a frequency of $50 \mathrm{~Hz}$, an intensity between 15 and $20 \mathrm{~mA}$, and a pulse width between 0.1 and $0.3 \mathrm{msec}$, with a time on-off ratio of 4:8 seconds. Its intensity was determined according to the child's comfort level, and was maintained at a level below the pain threshold that was well tolerated by the child [21]. Each session lasted 30 minutes, divided equally between the right and left pudendal nerves (15 minutes each). Sessions were performed 3 times per week for 3 successive months.

\section{Behavioral therapy}

All children in the 3 groups underwent behavioral therapy, which was reinforced at every session after beginning the treat- 
ment. The children and their parents were provided with simple explanations about normal bladder function and the proper voiding mechanism. Optimal voiding posture was practiced in order to achieve optimal toilet training. They were instructed to avoid foods or drinks with a diuretic or irritant impact, and to limit liquid intake for 3 hours before sleeping. Constipation management through a high-fiber diet and stool regulation was prompted, and children were asked to sit on the toilet 3 times per day after each meal. Alarm training was also encouraged by waking up the child periodically to void, in order to reinforce the child's arousal from sleep and to promote a rapid response to alarm triggering. Rewards were also used for dry nights and bladder training, including emptying the bladder before going to bed and after waking up [12].

\section{Pelvic floor muscles training}

In addition to behavioral therapy, all children in the 3 groups underwent PFMs training using Kegel exercises. Children were instructed to practice 3 sets of 30 repetitions of PFMs training in the crook-lying position with 10 seconds of contraction and 10 seconds of relaxation for 30 minutes without activating the hip or abdominal muscles $[10,13]$. All children underwent 3 sessions per week under the therapist's supervision and as a home routine on the other days for 3 successive months.

\section{Statistical Analysis}

IBM SPSS Statistics ver. 23.0 (IBM Co., Armonk, NY, USA) was used for the statistical analysis of data. The Shapiro-Wilk test was used to check whether the data had a normal distribution. The mean and standard deviation were calculated for all measured variables as descriptive statistics, with the sole exception of wet night episodes, which were expressed as a percentage. The paired $\mathrm{t}$-test was used to compare the pre- and posttreatment values of PFM activity (peak and speed) and bladder capacity within each group. Analysis of variance was conducted to compare the mean values of the measured variables among the 3 groups before and after treatment using the post hoc test for pair wise comparisons. The independent $\mathrm{t}$-test was used to compare the pre- and posttreatment values of nocturnal bladder capacity on dry and wet nights in the 3 groups. Additionally, the chi-square test was used to compare the frequency of wet nights within each group and among the 3 groups before and after treatment. Results were considered statistically significant at $\mathrm{P}$-values $<0.05$.

\section{RESULTS}

A total of 90 children with refractory PMNE were enrolled in this study. There were no significant differences among the 3 groups with respect to age $(\mathrm{P}=0.916)$, height $(\mathrm{P}=0.876)$, or weight $(\mathrm{P}=$ 0.829). Moreover, no significant differences were observed among the 3 groups regarding the pretreatment mean values of PFMs activity peak $(\mathrm{P}=0.341)$, speed $(\mathrm{P}=0.566)$, nocturnal bladder capacity $(\mathrm{P}=0.937)$, nocturnal bladder capacity on dry nights $(\mathrm{P}=$ 0.968), nocturnal bladder capacity on wet nights $(\mathrm{P}=0.962)$, or

Table 1. Demographic and baseline characteristics of the participating children

\begin{tabular}{|c|c|c|c|c|}
\hline Parameter & CON group $(n=30)$ & $B F$ group $(n=30)$ & ES group $(n=30)$ & P-value \\
\hline Age (yr) & $10.10 \pm 1.56$ & $9.93 \pm 1.61$ & $10.00 \pm 1.46$ & 0.916 \\
\hline Height $(\mathrm{cm})$ & $136.50 \pm 8.16$ & $137.06 \pm 7.07$ & $135.80 \pm 8.14$ & 0.876 \\
\hline Weight $(\mathrm{kg})$ & $30.96 \pm 4.50$ & $32.00 \pm 4.65$ & $31.20 \pm 4.40$ & 0.829 \\
\hline \multicolumn{5}{|l|}{ Sex } \\
\hline Boys & $27(90)$ & $24(80)$ & $26(86.7)$ & \\
\hline Girls & $3(10)$ & $6(20)$ & $4(13.3)$ & \\
\hline PFMs activity peak $(\mu \mathrm{V})$ & $93 \pm 7.6$ & $93.2 \pm 7.1$ & $95.6 \pm 8.1$ & 0.341 \\
\hline PFMs activity speed ( $\mu \mathrm{V} / \mathrm{sec})$ & $11.8 \pm 1.4$ & $12 \pm 1.4$ & $12.2 \pm 0.8$ & 0.566 \\
\hline Nocturnal bladder capacity (mL) & $112 \pm 29.7$ & $113 \pm 27.8$ & $110.3 \pm 29.6$ & 0.937 \\
\hline Nocturnal bladder capacity on dry nights & $122.5 \pm 12.58$ & $122 \pm 16.43$ & $120 \pm 14.14$ & 0.968 \\
\hline Nocturnal bladder capacity on wet nights & $110.38 \pm 31.43$ & $111.2 \pm 29.48$ & $108.84 \pm 30.63$ & 0.962 \\
\hline Frequency of wet nights (\%) & 94.1 & 92.4 & 93.4 & 0.361 \\
\hline
\end{tabular}

Values are presented as mean \pm standard deviation or number (\%).

CON, control; BF, biofeedback; ES, electrical stimulation; PFMs, pelvic floor muscles. 
Table 2. Comparison of the mean values of pelvic floor muscles activity (peak and speed), nocturnal bladder capacity, and frequency of wet nights within each group

\begin{tabular}{|c|c|c|c|c|c|c|c|c|c|}
\hline \multirow{2}{*}{ Parameter } & \multicolumn{2}{|c|}{ CON group $(n=30)$} & \multirow{2}{*}{ P-value } & \multicolumn{2}{|c|}{ BF group $(n=30)$} & \multirow{2}{*}{$\mathrm{P}$-value } & \multicolumn{2}{|c|}{ ES group $(n=30)$} & \multirow{2}{*}{ P-value } \\
\hline & Pre & Post & & Pre & Post & & Pre & Post & \\
\hline $\begin{array}{l}\text { PFMs activity } \\
\text { peak }(\mu \mathrm{V})\end{array}$ & $93 \pm 7.6$ & $93.7 \pm 9.1$ & $0.018^{\mathrm{a}), *}$ & $93.2 \pm 7.1$ & $160.2 \pm 7$ & $0.000^{\mathrm{a}), *}$ & $95.6 \pm 8.1$ & $174.5 \pm 10.2$ & $0.000^{\mathrm{a}), *}$ \\
\hline $\begin{array}{l}\text { PFMs activity } \\
\text { speed }(\mu \mathrm{V} / \mathrm{sec})\end{array}$ & $11.8 \pm 1.4$ & $12.8 \pm 1.7$ & $0.017^{\mathrm{a}), *}$ & $12 \pm 1.4$ & $30.1 \pm 4.5$ & $0.000^{\mathrm{a}), *}$ & $12.2 \pm 0.8$ & $36 \pm 4.6$ & $0.000^{\mathrm{a}), *}$ \\
\hline $\begin{array}{l}\text { Nocturnal bladder } \\
\text { capacity }(\mathrm{mL})\end{array}$ & $112 \pm 29.7$ & $129.66 \pm 25.52$ & $0.000^{\mathrm{a}), *}$ & $113 \pm 27.8$ & $193.66 \pm 33.16$ & $0.000^{\mathrm{a}), *}$ & $110.3 \pm 29.6$ & $357.33 \pm 47.41$ & $0.000^{\mathrm{a}), *}$ \\
\hline $\begin{array}{l}\text { Frequency of wet } \\
\text { nights (\%) }\end{array}$ & 94.1 & 66.1 & $0.000^{\mathrm{b}), *}$ & 92.4 & 51.6 & $0.000^{\mathrm{b}), *}$ & 93.4 & 14.3 & $0.000^{\mathrm{b}), *}$ \\
\hline
\end{tabular}

Values are presented as mean \pm standard deviation or percentage.

CON, control; BF, biofeedback; ES, electrical stimulation; PFMs, pelvic floor muscles.

${ }^{\text {a) }}$ Paired t-test. ${ }^{\text {b) }}$ Chi-square test. ${ }^{*} \mathrm{P}<0.05$.

Table 3. Comparison of the mean values of nocturnal bladder capacity on dry and wet nights in the 3 groups

\begin{tabular}{|c|c|c|c|c|c|c|c|c|c|}
\hline \multirow{2}{*}{$\begin{array}{l}\text { Nocturnal bladder } \\
\text { capacity }(\mathrm{mL})\end{array}$} & \multicolumn{2}{|c|}{ CON group $(n=30)$} & \multirow{2}{*}{ P-value } & \multicolumn{2}{|c|}{ BF group $(n=30)$} & \multirow{2}{*}{$\mathrm{P}$-value } & \multicolumn{2}{|c|}{ ES group $(n=30)$} & \multirow{2}{*}{ P-value } \\
\hline & Dry nights & Wet nights & & Dry nights & Wet nights & & Dry nights & Wet nights & \\
\hline Pre & $122.5 \pm 12.58$ & $110.38 \pm 31.43$ & $0.154^{\mathrm{a})}$ & $122 \pm 16.43$ & $111.2 \pm 29.48$ & $0.18^{\mathrm{a})}$ & $120 \pm 14.14$ & $108.84 \pm 30.63$ & $0.416^{\mathrm{a})}$ \\
\hline Post & $132.85 \pm 26.14$ & $126.87 \pm 25.48$ & $0.531^{\mathrm{a})}$ & $202.22 \pm 33.87$ & $180.83 \pm 28.74$ & $0.083^{\mathrm{a})}$ & $364.4 \pm 48.05$ & $322 \pm 23.87$ & $0.037^{\mathrm{a}) * *}$ \\
\hline
\end{tabular}

Values are presented as mean \pm standard deviation.

$\mathrm{CON}$, control; BF, biofeedback; ES, electrical stimulation.

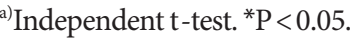

Table 4. Pair wise comparisons of pelvic floor muscles activity (peak and speed), nocturnal bladder capacity, and frequency of wet nights after treatment

\begin{tabular}{|c|c|c|c|c|c|c|c|}
\hline \multirow[b]{2}{*}{ Parameter } & \multicolumn{3}{|c|}{ Posttreatment } & \multirow[b]{2}{*}{$\mathrm{P}$-value } & \multicolumn{3}{|c|}{ P-value } \\
\hline & $\begin{array}{l}\text { CON group } \\
\quad(n=30)\end{array}$ & $\begin{array}{c}\text { BF group } \\
(\mathrm{n}=30)\end{array}$ & $\begin{array}{l}\text { ES group } \\
(n=30)\end{array}$ & & CON vs. BF & CONvs. ES & BF vs. ES \\
\hline PFMs activity peak $(\mu \mathrm{V})$ & $93.7 \pm 9.1$ & $160.2 \pm 7$ & $174.5 \pm 10.2$ & $0.000^{\mathrm{a}), *}$ & $0.000^{\mathrm{b}), *}$ & $0.000^{\mathrm{b}), *}$ & $0.000^{\mathrm{b}) * *}$ \\
\hline PFMs activity speed $(\mu \mathrm{V} / \mathrm{sec})$ & $12.8 \pm 1.7$ & $30.1 \pm 4.5$ & $36 \pm 4.6$ & $0.000^{\mathrm{a}) *}$ & $0.000^{\mathrm{b}), *}$ & $0.000^{\mathrm{b}), *}$ & $0.000^{\mathrm{b}), *}$ \\
\hline Nocturnal bladder capacity (mL) & $129.66 \pm 25.52$ & $193.66 \pm 33.16$ & $357.33 \pm 47.41$ & $0.000^{\mathrm{a}), *}$ & $0.000^{\mathrm{b}), *}$ & $0.000^{\mathrm{b}), *}$ & $0.000^{\mathrm{b}), *}$ \\
\hline Nocturnal bladder capacity on dry nights & $132.85 \pm 26.14$ & $202.22 \pm 33.87$ & $364.4 \pm 48.05$ & $0.000^{\mathrm{c}), *}$ & $0.000^{\mathrm{d}), *}$ & $0.000^{\mathrm{d}), *}$ & $0.000^{\mathrm{d}), *}$ \\
\hline Nocturnal bladder capacity on wet nights & $126.87 \pm 25.48$ & $180.83 \pm 28.74$ & $322 \pm 23.87$ & $0.000^{\mathrm{c}) * *}$ & $0.000^{\mathrm{d}), *}$ & $0.000^{\mathrm{d}) * *}$ & $0.000^{\mathrm{d}) * *}$ \\
\hline Frequency of wet nights (\%) & 66.1 & 51.6 & 14.3 & $0.000^{\mathrm{e}), *}$ & $0.000^{\mathrm{e}), *}$ & $0.000^{\mathrm{e}), *}$ & $0.000^{e), *}$ \\
\hline
\end{tabular}

Values are presented as mean \pm standard deviation or percentage.

CON, control; BF, biofeedback; ES, electrical stimulation; ANOVA, analysis of variance.

${ }^{\text {a) }}$ One-way ANOVA. ${ }^{\text {b) }}$ Post hoc least significant difference test. ${ }^{\text {c) }}$ ANOVA (Welch test). ${ }^{\text {d) }}$ Post hoc Games-Howell test. ${ }^{\text {e) }}$ Chi-square test. ${ }^{*} \mathrm{P}<0.05$.

frequency of wet nights $(\mathrm{P}=0.361)$, as shown in Table 1 .

Table 2 presents the results of within-group comparisons for PFM activity peak and speed, nocturnal bladder capacity, and frequency of wet nights. When comparing the pre- and posttreatment mean values, statistically significant improvements were found in all measured variables in all groups.
Table 3 shows the results of comparisons of nocturnal bladder capacity on dry and wet nights in the 3 groups. There were no significant differences between the pre- and posttreatment mean values of nocturnal bladder capacity on dry and wet nights in the 3 groups $(\mathrm{P}>0.05)$; however, a statistically significant improvement was observed when comparing the posttreatment mean 
Table 5. Clinical response of children in the 3 groups throughout the period of treatment according to the percentage of reduction in wet nights

\begin{tabular}{|c|c|c|c|}
\hline Variable & Nonresponse $(<50 \%)$ & Partial response (50\%-99\%) & Response (100\%) \\
\hline \multicolumn{4}{|c|}{ First month posttreatment } \\
\hline CON group & $30(100)$ & - & - \\
\hline BF group & $30(100)$ & - & - \\
\hline ES group & $30(100)$ & - & - \\
\hline \multicolumn{4}{|c|}{ Second month posttreatment } \\
\hline CON group & $30(100)$ & - & - \\
\hline BF group & $30(100)$ & - & - \\
\hline ES group & $7(23.3)$ & $23(76.6)$ & - \\
\hline \multicolumn{4}{|c|}{ Third month posttreatment } \\
\hline CON group & $23(76.6)$ & $7(23.3)$ & - \\
\hline BF group & $12(40)$ & $18(60)$ & - \\
\hline ES group & - & $26(86.7)$ & $4(13.3)$ \\
\hline
\end{tabular}

Values are presented as number (\%).

CON, control; BF, biofeedback; ES, electrical stimulation.

values of bladder capacity on dry and wet nights in the ES group $(\mathrm{P}=0.037)$.

Comparisons among the 3 groups indicated statistically significant differences in all outcome measures after treatment $(\mathrm{P}=0.000)$. Pair wise comparisons demonstrated statistically significant differences between the $\mathrm{CON}$ and BF groups, the $\mathrm{CON}$ and $\mathrm{ES}$ groups, and the BF and ES groups in all measured variables, with greater improvements in the ES group, as shown in Table 4.

Table 5 summarizes the clinical response to treatment according to the percentage of reduction in wet nights. After the first month of treatment, all children in the 3 groups were nonresponders. By the end of the third month of treatment, $23.3 \%$ and $60 \%$ of children became partial responders in the CON and $\mathrm{BF}$ groups, respectively, while $86.7 \%$ became partial responders and $13.3 \%$ became responders in the ES group.

\section{DISCUSSION}

The current study aimed to investigate the most appropriate method for improving PFM function, nocturnal bladder capacity, and wet night episodes by comparing the effects of intraanal BF training and intra-anal ES. The widespread use of parasacral transcutaneous ES and perineal BF training for the treatment of PMNE in children led us to evaluate the safety and effectiveness of intra-anal stimulation. To the best of our knowledge, no similar study has evaluated and compared the effects of intra-anal BF training with intra-anal ES in the management of children with PMNE. The results of this study support the use of both treatment methods in children with PMNE, with ES being more effective than BF training.

The present study revealed that all children in the 3 groups showed significant improvements in PFMs activity peak and speed, nocturnal bladder capacity, and frequency of wet nights. This could be attributed to the combined effect of behavioral therapy and PFM training, both of which play an essential role in enhancing urinary function in children with PMNE. This is in agreement with Prasad and Singh [25], who reported that behavioral therapy helped to correct the extrinsic body mechanism, advancing children's awareness of their pelvic components and their physiological functions and stimulating the active participation of children in correcting their habits. Additionally, Zivkovic et al. [26] concluded that PFM training had a significant impact on improving children's urinary functions, voiding muscle control, and bladder capacity. They reported that PFM training with behavioral therapy provided a helpful way to improve the performance of urinary and bowel function.

The significant improvements in all measured variables in the BF group is in agreement with Topaloğlu et al. [14], who found that EMG BF-assisted PFMs training improves PFMs function in children with enuresis more rapidly than PFM training alone. BF training enhances the capacity to practice contraction and relaxation of the sphincters and to recognize and make voluntary use of the PFMs. Additionally, it helps in strengthening lax PFMs and permits effective relaxation of the bladder neck with coordinated synergistic voiding [23]. 
The improvement of nocturnal bladder capacity in the BF group could be explained by the work of Kaye and Palmer [27], who found a significant increase of the bladder capacity in children with refractory PMNE after BF training. They concluded that animated BF games played an essential role in entertaining children, such that contraction and relaxation of the external sphincter more rapidly resulted in improved vesico-sphincter coordination and a significant reduction in wet night episodes. Moreover, biofeedback PFMs training modulates bladder instability by stimulating the detrusor inhibitory reflex, leading to improvement of the bladder capacity and bladder tone modulation [13].

The significant improvement in all measured outcomes in the ES group might be attributed to the pudendal nerve stimulation, which improves the PFMs contraction capability, thereby increasing urethral tension and leading to improvements in bladder capacity and reduction in wet night episodes. This is in accordance with De Oliveira et al. [15], who reported a significant decrease of enuresis frequency in children with PMNE after ES due to improvements in their bladder capacity. These findings could be explained by the work of Kajbafzadeh et al. [17], who found that stimulation of the afferent fibers of the pudendal nerve may reinforce the striated urethral muscles, increasing the conduction velocity of the pudendal and tibial nerves, improving neural efficiency through the regulation of afferent/efferent signals, and normalizing the voiding pattern in children with PNE.

Furthermore, Bergquist et al. [28] reported that direct stimulation of the nerve was more beneficial than stimulation of the muscle, as the central mechanism (H-reflex) was 2 to 3 times larger, while the peripheral mechanism (M-wave) was 5 to 6 times smaller. Additionally, direct nerve stimulation specifically targets the axons and branches, resulting in a wide stimulation pattern and an increased conduction velocity [29].

The significant differences between groups posttraining regarding PFM activity peak and speed, nocturnal bladder capacity on dry and wet nights, and frequency of wet nights in favor of the ES group could be explained by the work of De Gennaro et al. [30], according to whom ES helps to reestablish the balance between facilitatory and inhibitory control by means of enhancing peripheral and central neuroplasticity. The peripheral effect is accomplished through stimulating PFM contraction, facilitating the micturition reflex arc and urethral closure. The central effect is achieved by the restoration of brainstem and cortical activities; as the reflexive activation of sympathetic in- hibitory neurons evoked by pudendal nerve stimulation takes place, with central inhibition of parasympathetic excitatory neurons of the bladder, bladder overactivity is simultaneously reduced. Via neuroplasticity, synaptic remodulation modifies the neurotransmission processes, improving $\beta$-adrenergic activity and decreasing cholinergic activity, thereby causing detrusor muscle relaxation [31].

Additionally, ES has some advantages over BF training, as it provides a nonselective, spatially fixed, and temporally synchronous stimulated pattern, rather than a pattern that occurs during voluntary contraction [29]. It nonspecifically stimulates both fast and slow fibers at either low or high intensity. The fasttwitch striated muscle fibers of the external anal sphincter contract and relax more rapidly than the slow-twitch smooth muscle fibers of the internal anal sphincter [32]. Moreover, stimulation of contraction of the striated urethral muscles causes enlargement of the muscle fibers, with faster conduction of motor unit recruitment [30]. ES activates these smooth muscle fibers, which are difficult to reach by active exercises [33].

In the present study, the improvement of PFMs activity in both study groups is in accordance with the results presented by Demirturk et al. [34], who compared the effects of interferential current and BF on PFMs strength and incontinence severity in subjects with urinary incontinence. They concluded that both techniques were effective in enhancing PFMs strength and promoting incontinence control. However, both methods seemed to result in a similar amount of improvement. Nevertheless, they recommended further studies to identify clinically useful differences between the 2 methods.

The results of the present study revealed that nocturnal bladder capacity was greater on dry nights than on wet nights in all 3 groups, but this difference was only significant in the ES group. This could be attributed to the effect of pudendal nerve stimulation on NE improvement. Children in all 3 groups showed a positive response to the intervention, with a significant reduction in the frequency of wet nights in favor of the ES group. All children had normal daytime bladder storage capacity, as they did not experience daytime enuresis events. Their bladder capacity only became reduced in association with the appearance of nocturnal detrusor disinhibition after sleep, resulting in frequent bedwetting. At the same time, the children experienced difficulties with conscious arousal and waking up to void in response to the sensation of a full bladder. In the light of these facts, bladder capacity on wet and dry nights may not necessarily be an all-or-none or absolute phenomenon, but 
rather a relative phenomenon, depending on its relationship with urine production at night and the FMV volume. Various factors may affect nocturnal urine production and bladder storage function, either alone or in combination, and contribute to an imbalance or mismatch between these parameters in children with NE.

The present study has some limitations, including a lack of long-term follow-up. Furthermore, the fact that both study groups shared the effects of behavioral therapy and PFMs training limits the degree to which the benefits of $\mathrm{BF}$ training and ES alone can be identified. Future studies are warranted to determine the need for further maintenance treatment to provide maximal and sustained benefits.

In conclusions, intra-anal BF and intra-anal ES can be used effectively for the treatment of children with PMNE refractory to medical treatment. Both treatment methods can be used in clinical practice, as they were well tolerated with the protocol that we used, which provided a basis for safe and efficacious stimulation, as no adverse effects were observed during the study period. However, ES appeared to be a significantly more effective therapeutic modality.

\section{ACKNOWLEDGEMENTS}

The authors would like to express their appreciation to the children and their caregivers for their co-operation and participation in this study.

\section{AUTHOR CONTRIBUTION STATEMENT}

- Full access to all the data in the study and takes responsibility for the integrity of the data and the accuracy of the data analysis: $S A E, M S, S M A$

- Study concept and design: $S A E, M S$

- Acquisition of data: SAE, SMA

- Analysis and interpretation of data: SAE, MS, SMA

- Drafting of the manuscript: SAE, SMA

- Critical revision of the manuscript for important intellectual content: $S A E, M S$

- Statistical analysis: SAE, SMA

- Administrative, technical, or material support: SAE, MS, SMA

- Study supervision: $S A E, M S$

\section{REFERENCES}

1. Neveus T, Eggert P, Evans J, Macedo A, Rittig S, Tekgül S, et al. Evaluation of and treatment for monosymptomatic enuresis: a standardization document from theInternational Children's Continence Society. J Urol 2010;183:441-7.

2. Austin PF, Bauer SB, Bower W, Chase J, Franco I, Hoebeke P, et al. The standardization of terminology of lower urinary tract function in children and adolescents: update report from the Standardization Committee of the International Children's Continence Society. J Urol 2014;191:1863-5.e13.

3. Tugtepe H, Thomas DT, Ergun R, Kalyoncu A, Kaynak A, Kastarli C, et al. The effectiveness of transcutaneous electrical neural stimulation therapy in patients with urinary incontinence resistant to initial medical treatment or biofeedback. J Pediatr Urol 2015;11:137.e1-5.

4. Andersson KE, Arner A. Urinary bladder contraction and relaxation: physiology and pathophysiology. Physiol Rev 2004;84:935-86.

5. Holstege G, Mouton LJ. Central nervous system control of micturition. Int Rev Neurobiol 2003;56:123-45.

6. Podnar S, Trsinar B, Vodusek DB. Neurophysiological study of primary nocturnal enuresis. Neurourol Urodyn 1999;18:93-8.

7. Lv L, Deng H, Li X. Afferent pathway dysfunction in children with primary nocturnal enuresis. Int J Urol 2010;17:182-6.

8. Madill SJ, Pontbriand-Drolet S, Tang A, Dumoulin C. Effects of PFM rehabilitation on PFM function and morphology in older women. Neurourol Urodyn 2013;32:1086-95.

9. Guaderrama NM, Liu J, Nager CW, Pretorius DH, Sheean G, Kass$\mathrm{ab} \mathrm{G}$, et al. Evidence for the innervation of pelvic floor muscles by the pudendal nerve. Obstet Gynecol 2005;106:774-81.

10. Yamanishi T, Yasuda K, Murayama N, Sakakibara R, Uchiyama T, Ito $\mathrm{H}$. Biofeedback training for detrusor overactivity in children. J Urol 2000;164:1686-90.

11. Arda E, Cakiroglu B, Thomas DT. Primary nocturnal enuresis: a review. Nephrourol Mon 2016;8:e35809.

12. Caldwell PH, Deshpande AV, Von Gontard A. Management of nocturnal enuresis. BMJ 2013;347:f6259.

13. Sancak EB, Akbaş A, Kurt Ö, Alan C, Ersay AR. The effectiveness of biofeedback therapy in children with monosymptomatic enuresis resistant to desmopressin treatment. Turk J Urol 2016;42:278-84.

14. Topaloğlu N, Alan C, Ersay AR, Eren AE, Baştürk G, Alan H. Biofeedback in the treatment of nocturnal enuresis: may be an alternative method of treatment? J Clin Anal Med 2015;6:604-7.

15. de Oliveira LF, de Oliveira DM, da Silva de Paula LI, de Figueiredo AA, de Bessa J Jr, de Sá CA, et al. Transcutaneous parasacral electrical neural stimulation in children with primary monosymptom- 
atic enuresis: a prospective randomized clinical trial. J Urol 2013; 190:1359-63.

16. Raheem AA, Farahat Y, El-Gamal O, Ragab M, Radwan M, ElBahnasy AH, et al. Role of posterior tibial nerve stimulation in the treatment of refractory monosymptomatic nocturnal enuresis: a pilot study. J Urol 2013;189:1514-8.

17. Kajbafzadeh AM, Sharifi-Rad L, Mozafarpour S, Ladi-Seyedian SS. Efficacy of transcutaneous interferential electrical stimulation in treatment of children with primary nocturnal enuresis: a randomized clinical trial. Pediatr Nephrol 2015;30:1139-45.

18. Jørgensen CS, Kamperis K, Borch L, Borg B, Rittig S. Transcutaneous electrical nerve stimulation in children with monosymptomatic nocturnal enuresis: a randomized, Double-Blind, Placebo Controlled Study. J Urol 2017;198:687-93.

19. Halski T, Ptaszkowski K, Słupska L, Dymarek R. The evaluation of bioelectrical activity of pelvic floor muscles depending on probe location: a pilot study. Biomed Res Int 2013;2013:238312.

20. Stania M, Chmielewska D, Kwaśna K, Smykla A, Taradaj J, Juras G. Bioelectrical activity of the pelvic floor muscles during synchronous whole-body vibration--a randomized controlled study. BMC Urol 2015;15:107.

21. Suelena M, Doryaneb MD, Raphaela FR, Gustavob K, Kellib R, Marcielib S, et al. Effectiveness of treatment using fecal incontinence biofeedback isolated or associated with electrical stimulation. J Coloproctol 2014;34:240-4.

22. Grape HH, Dedering A, Jonasson AF. Retest reliability of surface electromyography on the pelvic floor muscles. Neurourol Urodyn 2009;28:395-9.

23. Herndon CD, Decambre M, McKenna PH. Interactive computer games for treatment of pelvic floor dysfunction. J Urol 2001;166:18938.

24. Hamdy S, Enck P, Aziz Q, Uengoergil S, Hobson A, Thompson DG. Laterality effects of human pudendal nerve stimulation on cortico- anal pathways: evidence for functional asymmetry. Gut 1999;45:5863.

25. Prasad V, Singh N. Effectiveness of non pharmacological therapy on bed wetting in children. J Drug Deliv Ther 2011;1:78-80.

26. Zivkovic V, Lazovic M, Vlajkovic M, Slavkovic A, Jovanovic Z. The role of pelvic floor rehabilitation in the treatment of children with dysfunctional voiding. J Pediatr Urol 2010;6(Suppl 1):S6-70.

27. Kaye JD, Palmer LS. Animated biofeedback yields more rapid results than nonanimated biofeedback in the treatment of dysfunctional voiding in girls. J Urol 2008;180:300-5.

28. Bergquist AJ, Wiest MJ, Collins DF. Motor unit recruitment when neuromuscular electrical stimulation is applied over a nerve trunk compared with a muscle belly: quadriceps femoris. J Appl Physiol (1985) 2012;113:78-89.

29. Bickel CS, Gregory CM, Dean JC. Motor unit recruitment during neuromuscular electrical stimulation: a critical appraisal. Eur J Appl Physiol 2011;111:2399-407.

30. De Gennaro M, Capitanucci ML, Mosiello G, Zaccara A. Current state of nerve stimulation technique for lower urinary tract dysfunction in children. J Urol 2011;185:1571-7.

31. Bower WF, Yeung CK. A review of non-invasive electro neuromodulation as an intervention for non-neurogenic bladder dysfunction in children. Neurourol Urodyn 2004;23:63-7.

32. Van Rey FS, Heesakkers JP. Applications of neurostimulation for urinary storage and voiding dysfunction in neurological patients. Urol Int 2008;81:373-8.

33. Vonthein R, Heimerl T, Schwandner T, Ziegler A. Electrical stimulation and biofeedback for the treatment of fecal incontinence: a systematic review. Int J Colorectal Dis 2013;28:1567-77.

34. Demirtürk F, Akbayrak T, Karakaya IC, Yüksel I, Kirdi N, Demirtürk F, et al. Interferential current versus biofeedback results in urinary stress incontinence. Swiss Med Wkly 2008;138:317-21. 